\title{
Reflexiones en torno a la diplomacia científica: estado del debate, experiencia internacional y perspectivas para Colombia
}

\author{
Gonzalo Ordóñez-Matamoros* \\ María Paula Roa González ${ }^{* *}$ \\ Juan Pablo Centeno***
}

\section{RESUMEN}

Si bien la relación entre ciencia y diplomacia es de vieja data, los esfuerzos por conceptualizarla a partir del siglo xxi dieron origen a la diplomacia cientifica, una noción impulsada de manera entusiasta por emprendedores de política, en particular en la Unión Europea. Sin embargo, la discusión en español sobre este concepto emergente es aún escasa y poco crítica, por lo que en este artículo de reflexión se exploran las bases del concepto de diplomacia científica con el propósito de clarificar sus alcances. Repasamos las principales definiciones de la diplomacia científica y mapeamos el avance en la producción de conocimiento sobre la misma. Encontramos que se trata de un campo emergente, con arraigo disciplinar

* Doctor en políticas públicas. Director del Centro de Investigaciones y Proyectos Especiales, Cipe. Facultad de Finanzas, Gobierno y Relaciones Internacionales, Universidad Externado de Colombia, Bogotá (Colombia). Profesor asistente de la Universidad de Twente. [gonzalo.ordonez@uexternado.edu.co]; [https://orcid.org/0000-0002-82976554].

** Estudiante de décimo semestre de gobierno y relaciones internacionales con enfoque en gerencia pública. Auxiliar de investigación del Centro de Investigaciones y Proyectos Especiales, Cipe. Universidad Externado de Colombia, Bogotá. [maria.roa04@est.uexternado.edu.co], [https://orcid.org/0000-0002-8727-1852].

*** Magíster en gobierno y políticas públicas. Investigador del Centro de Investigaciones y Proyectos Especiales, Cipe, Universidad Externado de Colombia, Bogotá. [juan.centeno@uexternado.edu.co]; [https://orcid.org/0000-00028068-4267].

Recibido: 1 de diciembre de 2020 / Modificado: 10 de febrero de 2021 / Aceptado: 22 de febrero de 2021

Para citar este artículo:

Ordóñez-Matamoros, G.; Roa González, M. P. y Centeno, J. P. (2021). Reflexiones en torno a la diplomacia científica: Estado del debate, experiencia internacional y perspectivas para Colombia. OASIS, 34, pp. 13-38

DoI: https://doi.org/10.18601/16577558.n34.03 
en la tradición de las relaciones internacionales y de base empírica multisectorial, preocupada esencialmente por retos ambientales desde el Norte Global. Asimismo, examinamos algunas experiencias internacionales que ilustran las posibles perspectivas y condiciones de viabilidad de la diplomacia científica en Colombia. $\mathrm{El}$ artículo concluye con algunas reflexiones críticas sobre el concepto.

Palabras clave: Diplomacia científica, ciencia y tecnología, política exterior, política de innovación, relaciones internacionales, cooperación científica.

\section{Reflections on science diplomacy: State of the debate, international experiences and perspectives for Colombia}

\section{ABSTRACT}

Although the relationship between science and diplomacy is quite old, efforts to conceptualize it since the beginning of the $21^{\text {st }}$ century gave birth to science diplomacy, a notion enthusiastically promoted by policy entrepreneurs, especially in Europe. However, discussions in Spanish on this emergent concept are still scarce and rather uncritical, so, in this reflection article the foundations of the concept of science diplomacy are explored with the purpose of clarifying its scope. We go over the main definitions of science diplomacy and map the evolutions of knowledge production on this topic. We find an emergent field, mainly based on the international relations tradition and with a multisectoral empirical ground, are essentially concerned with environmental challenges from the Global North. Also, we examine some international experiences that enlighten the possible perspectives and conditions for science diplomacy to be viable in the case of Colombia. The article concludes with some critical reflections on the concept.

Key words: Science diplomacy, Science $\&$ technology, Foreign policy, Innovation policy, International relations, Science cooperation

\section{INTRODUCCIÓN}

El mundo enfrenta grandes retos en materia social, económica y ambiental, los cuales transgreden las fronteras de los Estados y demandan acción concertada entre distintos países. Problemas de escala global como el cambio climático, la ciberpiratería, las guerras comerciales, las migraciones, la seguridad alimentaria y las amenazas a la salud, como la pandemia del Covid-19, entre otros, implican repensar las aproximaciones tradicionales sobre las relaciones entre Estados, en favor de formas más provechosas de interacción (ya sea cooperativa o competitiva) entre estos para el abordaje de dichos retos.

Este tipo de retos exige soluciones novedosas basadas en la interacción entre actores y el conocimiento, que aprovechen las fortalezas de cada país, así como sus nichos de innovación, talento y competitividad. Aquí, la ciencia, la tecnología y la innovación (CTeI) representan un medio necesario para la adopción de acciones que contribuyan a construir un desarrollo socioeconómico sostenible, las 
cuales pueden apoyarse en las relaciones internacionales para proyectar soluciones a escala global. Las mismas CTeI generan también nuevos problemas. Este encuentro entre la СТеI y las relaciones internacionales, de creciente relevancia, supone entonces una serie de lógicas, herramientas de poder, principalmente blando, con las que cuentan los gobiernos para viabilizar sus intereses nacionales por la vía de la interacción con otros.

En este contexto, surge la diplomacia cientifica, un concepto emergente en el campo de las relaciones internacionales, que implica nuevos puentes entre la ciencia, las políticas públicas y la diplomacia, habitualmente pensadas como esferas o mundos separados. Vale anotar que la diplomacia científica involucra dinámicas con larga tradición de ocurrencia, y que debido a los apenas recientes esfuerzos de conceptualización promovidos principalmente en Europa se encuentra en proceso de 'renovación'. Este concepto supone una nueva aproximación interdisciplinaria a la cooperación e interacción entre Estados para mejorar las políticas y la gestión pública en pro del desarrollo socioeconómico, la competitividad, la inclusión social, la consolidación de ciudades inteligentes, la promoción de nuevas tecnologías, entre otros propósitos.

En el presente artículo de reflexión exploramos las bases del concepto de diplomacia científica con el propósito de clarificar sus alcances. Concretamente, en primer lugar discutimos en torno al potencial y los vacíos presentes en la interfaz ciencia-diplomacia como base del concepto, para lo cual repasamos las definiciones propuestas en la literatura para explicar este tipo de diplomacia. En segundo lugar, mapeamos el avance en la producción de conocimiento sobre diplomacia científica con el fin de dar cuenta de los alcances de este campo analítico y de práctica emergente. En tercer lugar, identificamos algunas experiencias internacionales que ilustran este tipo de práctica, para luego, en cuarto lugar, reflexionar sobre las condiciones necesarias para implementar una estrategia de diplomacia científica en Colombia, discutiendo sobre las perspectivas, oportunidades y retos para la diplomacia científica en el país. Finalmente, el texto concluye con algunas reflexiones sobre posibles futuras líneas de indagación en relación con la diplomacia científica. La estructura del artículo se desarrolla en este mismo orden.

Esperamos con este artículo contribuir a una mejor comprensión sobre los alcances del concepto de diplomacia científica, así como a una mayor promoción de la misma para el logro de objetivos globales.

\section{INTERFAZ CIENCIA-DIPLOMACIA: BASES DE LA DIPLOMACIA CIENTÍFICA}

La diplomacia científica es un concepto que surge en un contexto en el que los retos globales requieren de intervenciones concertadas entre distintos gobiernos y actores alrededor del mundo, lo cual, en buena medida, impugna la concepción westfaliana tradicional del Estado-Nación y empuja el campo de las relaciones internacionales hacia temas poco tratados antes como el del papel de la ciencia (Flink \& Schreiterer, 2009; Turekian y otros, 2015). Distintos hitos se destacan en la promoción del concepto, como lo ha sido el trabajo de la Asociación Americana para el Avance de 
la Ciencia con la creación, en 2008, del Centro para la Diplomacia Científica y el lanzamiento en 2012 de la revista Ciencia y Diplomacia (The Parliamentary Office of Science and Technology, 2018). También destaca el papel de la Sociedad Real para el Avance de la Ciencia, del Reino Unido, y más recientemente el Programa Marco de la Unión Europea Horizonte $2020^{1}$.

Por un lado, algunas definiciones de diplomacia científica tienden a atribuir un carácter instrumental a la ciencia en pro de la práctica diplomática. En ese sentido, la diplomacia científica puede ser entendida como "el uso de colaboraciones científicas entre naciones para abordar los problemas comunes que la humanidad del siglo 21 enfrenta, y para construir alianzas internacionales constructivas" (Fedoroff, 2009, p. 9) o como

una técnica diplomática a través de la cual el conocimiento científico y tecnológico es liberado de sus rígidas fronteras nacionales e institucionales, revelando así su potencial para abordar directamente las causas del subdesarrollo y la inseguridad (sic) (Copeland, 2016, p. 629).

Por otro lado, existe una aproximación más amplia al concepto de diplomacia científica, en la que esta es concebida como un concepto 'sombrilla' que abarca una serie de prácticas multisectoriales, ya sea formales o informales, que tienen lugar en la interfaz entre ciencia y diplomacia (Basha, 2016; citado en Rungius, 2018). En esa línea, la Sociedad Real de Londres para el Avance de la Ciencia Natural (Royal Society) (2010) identifica tres dimensiones que contribuyen a configurar el concepto de diplomacia científica, en el que la сте tienen un rol central en materia de política exterior, a saber: i) la ciencia en la diplomacia, en el que la ciencia informa y apoya la toma de decisiones de política exterior; ii) la diplomacia para la ciencia, que busca facilitar la cooperación científica entre Estados; y iii) la ciencia para la diplomacia, en la que se usa la cooperación científica como mecanismo para estrechar lazos entre Estados (ver figura 1).

Figura 1.
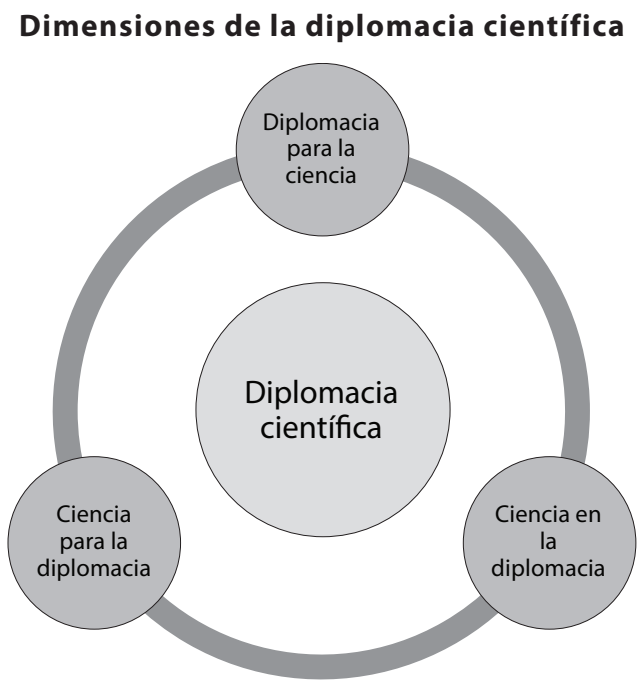

Fuente: Royal Society (2010).

1 Para una lectura mucho más detallada del estado del arte, la evolución de este concepto y su promoción en esferas de política, recomendamos los textos de Rungius (2018), Turekian (2018) y Rungius \& Flink (2020). 
En este marco, múltiples mecanismos y prácticas se desarrollan dentro de la interfaz ciencia-diplomacia, como lo son, por ejemplo, la construcción de redes internacionales de investigación y de toma de decisiones, la suscripción de acuerdos multilaterales de promoción de la ciencia, la creación o consolidación de sociedades y academias científicas, la financiación multilateral de programas de investigación, la colaboración en torno a laboratorios e instalaciones científicas internacionales, la diáspora y retorno de investigadores entre países, entre otros (The Parliamentary Office of Science and Technology, 2018).

Una propuesta alternativa a las tres dimensiones de la figura 1 es la de Gluckman et al. (2017), quienes argumentan que la distinción entre las anteriores dimensiones no es lo suficientemente clara ni mutuamente excluyente. En ese sentido, desde un punto de vista pragmático, los autores proponen tres categorías alternativas de diplomacia científica: i) aquella con acciones orientadas a la consecución de los intereses nacionales, ii) aquella orientada al abordaje de retos transfronterizos y iii) aquella que busca el logro de propósitos globales.

Independientemente de dichas dimensiones, son diversos los actores que pueden involucrarse en procesos de diplomacia científica, ya sea por el interés de incorporar la ciencia dentro de la política exterior de un gobierno con el fin de viabilizar relaciones de cooperación con otros actores, o por el carácter supranacional de las prácticas científicas que compiten en un escenario global de producción de conocimiento (López \& Schunz, 2017).
Si bien la diplomacia científica es un concepto fluido y emergente, con diversas interpretaciones y conceptualizaciones, la mayoría de las definiciones tienden a coincidir en la necesidad de que el Estado ejerza una acción para encontrar puntos de común acuerdo, sinergias y herramientas para desplegar estrategias que promuevan la colaboración y competitividad global (The Royal Society, 2010). Bajo este panorama, impulsar el avance de la ciencia como propósito del Estado-Nación es un menester atribuible principalmente a los ministerios de CTeI, pero también, y crecientemente, a las cancillerías o ministerios de asuntos exteriores. Esto, con el fin de afrontar retos globales cuyo abordaje puede apoyarse en el conocimiento científico-tecnológico en la esfera de la negociación internacional. En ese sentido, la internacionalización de la ciencia y la tecnología necesita que la cooperación internacional sea una responsabilidad compartida por todos los agentes de la administración pública, además de la inclusión de otros actores que también son esenciales para el aprovechamiento de dichas actividades en todos los niveles de gobierno.

De cualquier modo, además de los actores estatales - ministerios, embajadas, cancillerías, agencias públicas, agencias de financiación, gobiernos subnacionales, entre otros- la diplomacia científica implica la participación de múltiples actores tales como las organizaciones internacionales y supranacionales, actores de la academia como las universidades, centros de investigación, academias nacionales y sociedades científicas; el sector privado con multinacionales, pequeñas y me- 
dianas empresas de alta tecnología o de base científico-tecnológica; y actores de la sociedad civil como asociaciones, fundaciones privadas y activistas. En suma, si bien es posible identificar a lo largo de la historia múltiples ejemplos de dinámicas que involucran a la ciencia y la diplomacia, es necesario destacar que la diplomacia científica se destaca por su carácter estratégico basado en arreglos institucionales definidos, de modo que no se trata de una práctica espontánea carente de agenda pública (Turekian, 2018).

Ahora bien, la intersección entre ciencia y diplomacia implica el reconocimiento, promoción y entrenamiento de nuevos profesionales, capaces de entender las lógicas, tanto científicas como diplomáticas, su integración a procesos de negociación internacional con alto contenido científico-tecnológico, agentes de cambio e intermediarios capaces de 'traducir' y comunicarse con públicos diversos, activos participantes en comités y comisiones interministeriales de asesoramiento científico y diplomático, entre otros. Es con este tipo de profesionales que pueden sortearse los retos propios del carácter interdisciplinario, multisectorial, especializado e híbrido de los procesos de diplomacia científica, en los que convergen múltiples actores, políticas, funciones y niveles de decisión. Si bien no existen actualmente programas de formación explícitos para profesionales en diplomacia científica (Mauduit y Gual Soler, 2020), es posible identificar al menos dos roles con algún grado de institucionalización que se acercan al perfil mencionado arriba: se trata de los diplomáticos científicos oficiales y los asesores científicos gubernamentales (Melchor, 2020).

Frente a este panorama, es importante avanzar en el fomento y formalización de un nuevo profesional que pueda estar en capacidad de agenciar vías de diálogo entre países en materia con alto contenido científico; un profesional formado en las bases del pensamiento científico y su gobernanza, y entrenado en el análisis y la práctica de la política exterior, las relaciones internacionales y la diplomacia; un profesional con habilidades blandas para intermediar entre múltiples actores y organizaciones con agendas propias, con el fin de crear acuerdos e intercambios que contribuyan a una mejor posición nacional y un mayor bienestar global.

En suma, promover relaciones más provechosas entre la ciencia y la diplomacia debe ser un pilar en la política exterior, sobre todo en un contexto globalizado de rápido cambio tecnológico al que la legislación responde con menor velocidad. En ese sentido, la diplomacia científica agrupa todas aquellas actuaciones que interrelacionan las relaciones internacionales y la política científica, y que suponen la posibilidad de compartir investigaciones y conocimientos más allá de las fronteras políticas, así estas estén divorciadas o tensas entre países.

Ahora bien, como interfaz entre conocimiento y ciencia, la producción de conocimiento sobre diplomacia científica sugiere la intersección entre diversos campos de estudio. Por esta razón, en la sección siguiente exploramos las dinámicas de producción bibliográfica en torno a este concepto. 


\section{DIPLOMACIA CIENTÍFICA COMO}

\section{CAMPO ANALÍTICO EMERGENTE}

En esta sección nos enfocamos entonces ya no en el concepto implícito y multivariado de la práctica de la diplomacia científica, tal y como se presenta, sino en los patrones de producción de conocimiento sobre la misma. Con esto es posible identificar las principales características de este campo interdisciplinar de fronteras cognitivas y sectoriales porosas, que presenta una larga tradición práctica, pero emergente en términos analíticos como objeto de estudio.

Para esto, se realizó una búsqueda de documentos -con propósitos ilustrativos mas no comprehensivos- en la base de datos Scopus, en donde se identificaron un total de 167 documentos, en su mayoría artículos de investigación (ver figura 2), que incluían la expresión science diplomacy (diplomacia científica) bien sea en su título, resumen o palabras clave ${ }^{2}$.

Aquí nos centramos en los patrones de producción de conocimiento desde el punto de vista de, primero, su evolución en el tiempo; segundo, su procedencia geográfica; y tercero, los campos disciplinares desde los que se discute sobre diplomacia científica junto con las palabras clave que indican los temas recurrentes y emergentes en torno a las reflexiones sobre diplomacia científica.

\section{Figura 2}

\section{Tipos de documentos sobre diplomacia} científica en Scopus $(\mathrm{N}=167)$

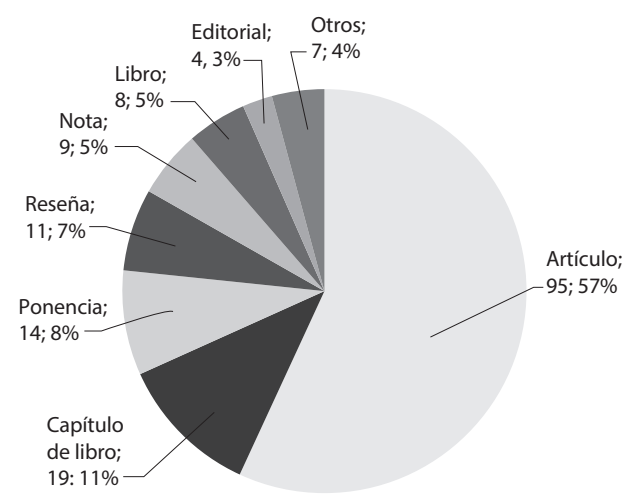

Fuente: Datos bibliográficos tomados de Scopus.

\subsection{Evolución en la producción de conocimiento sobre diplomacia científica}

En primer lugar, es posible identificar al menos tres momentos o etapas en la evolución de la producción de conocimiento sobre diplomacia científica (ver figura 3). En general, el gráfico ilustra que se trata de una discusión propia del siglo XXI, con esfuerzos mucho más decididos por conceptualizar dicha noción a pesar de la histórica relación entre ciencia y diplomacia en múltiples esferas de la escena global (Turekian, 2018; Rungius \& Flink, 2020).

\footnotetext{
2 La búsqueda se realizó con corte al 11 de noviembre de 2020. Dado el carácter ilustrativo de dicha búsqueda, y del tipo de documentos contenidos en la base de Scopus, debe tenerse en cuenta que esta no incluye las posibles conceptualizaciones que sobre diplomacia científica hacen diversos tipos de documentos de literatura gris, o en otros idiomas distintos al inglés. Se hace énfasis en artículos de investigación por tratarse de fuentes de nuevo conocimiento sobre el tema, que ofrece una mirada alternativa al tradicional impulso que se ha dado desde el emprendimiento institucional sobre el tema, fundamentalmente con literatura gris (e.g. policy briefs, documentos de política, reportes, etc.). El documento con fecha de 2021, a pesar de la fecha de corte de la búsqueda, consiste en un advanced-online publication.
} 
Figura 3

Evolución en la producción de conocimiento sobre diplomacia científica según número de documentos

por año en Scopus $(N=167)$

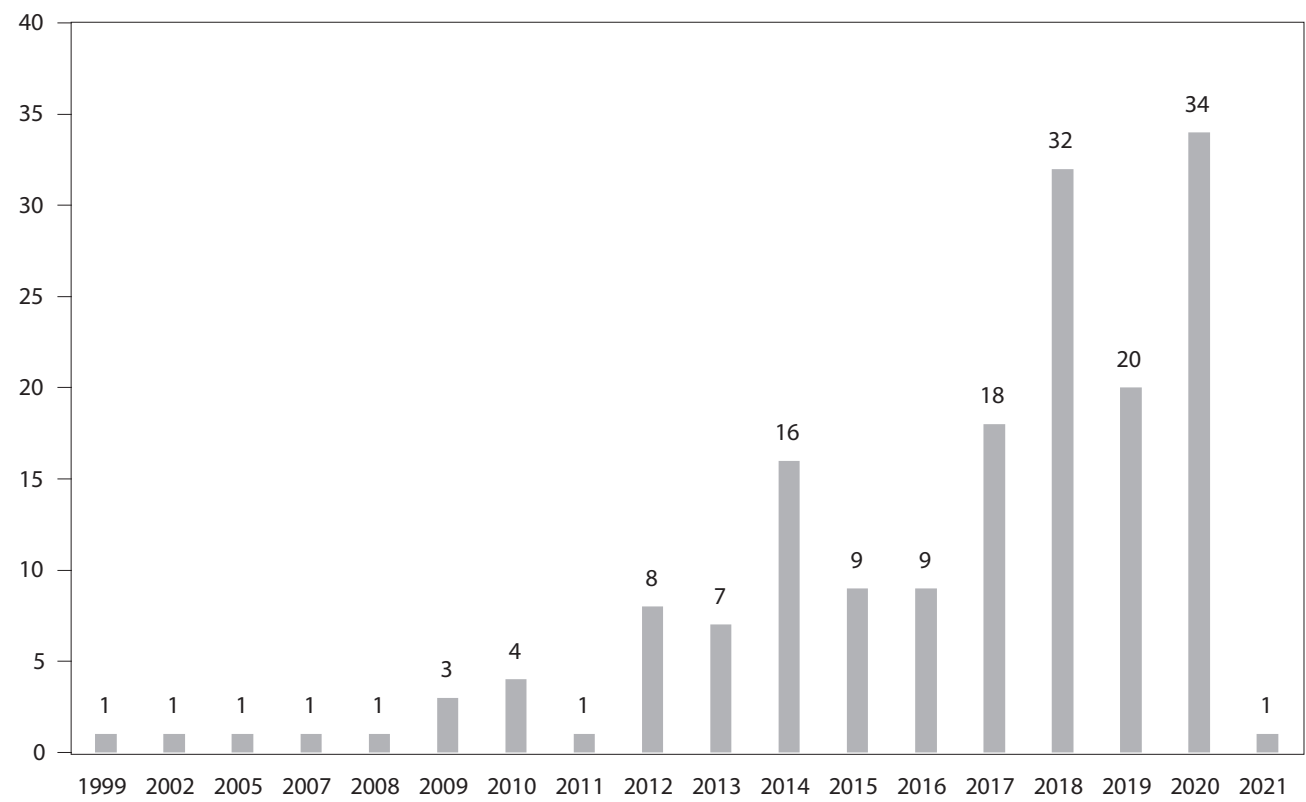

Fuente: Datos bibliográficos tomados de Scopus.

La primera etapa muestra una producción periódica durante la primera década de XXI (1999-2010), con preocupación por el rol de la ciencia a nivel global en materia energética (Ritch, 1999), biotecnológica (Juma, 2002), comercial (Vikhlyaev, 2005) y ambiental (Harris, 2009). Lo anterior impulsado por un giro en el rol que la ciencia desempeña en el escenario global, en donde pasa de ser concebida como un puente diplomático a un mecanismo para el abordaje de retos globales (Turekian, 2018).

Hacia el final de esta primera etapa se observa un aumento de producción, con dos documentos que destacan por su impacto (ver en tabla 1, el top 10 de documentos con mayor número de citas): en primer lugar, destaca el trabajo de Flink y Schreiterer (2010), quienes proponen algunas tipologías programáticas de diplomacia científica tras revisar seis casos internacionales, trabajo que se destaca como el mayor citado dentro de los documentos identificados. Los documentos divulgativos han sido importantes en el posicionamiento de la diplomacia científica como campo emergente, en donde se destaca el documento de Fedoroff (2009) quien repasa algunos de los rasgos y prácticas que caracterizan la diplomacia cien- 
tífica y propone una definición de la misma, tratándose del segundo documento con mayor cantidad de citaciones hasta el momento. Este aumento al final de la década coincide con el impulso y la promoción que algunas organizaciones realizaron sobre el tema como lo son la Asociación Americana para el Avance de la Ciencia $(2008$; 2012) y la Real Sociedad de Londres para el Avance de la Ciencia Natural (Royal Society), esta última con el influyente reporte titulado New Frontiers in Science Diplomacy (2010).
Posteriormente, en una segunda etapa entre 2011 y 2014, se observa un escalamiento importante de la producción. Destaca un aumento de la producción para 2012 con preocupaciones sectoriales (e.g. salud pública y gobernanza del agua) que reciben especial atención en regiones del mundo como Medio Oriente (Mojtahedi y Ghaderi, 2012; Megdal et al., 2012; Sarkadi y Schatten, 2012). En 2014 esta producción se duplica con la aparición de mayor cantidad de trabajos empíricos que ilustran las distintas formas que adopta la

Tabla 1

Top 10 artículos más citados sobre diplomacia científica

\begin{tabular}{|c|c|c|c|c|}
\hline Título & Autor & Año & Revista & $\begin{array}{l}\text { Número } \\
\text { de citas }\end{array}$ \\
\hline $\begin{array}{c}\text { Science diplomacy at the intersection of S\&T } \\
\text { policies and foreign affairs: Toward a typology of } \\
\text { national approaches }\end{array}$ & $\begin{array}{c}\text { Flink, T., } \\
\text { Schreiterer, U. }\end{array}$ & 2010 & $\begin{array}{l}\text { Science and Public Policy } \\
37 \text { (9), pp. } 665-677\end{array}$ & 44 \\
\hline Science Diplomacy in the 21st Century & Fedoroff, N.V. & 2009 & $\begin{array}{c}\text { Cell } \\
136(1), \text { pp. 9-11 }\end{array}$ & 28 \\
\hline Time for a new era of science diplomacy & $\begin{array}{l}\text { Lord, K.M., } \\
\text { Turekian, V.C. }\end{array}$ & 2007 & $\begin{array}{c}\text { Science } \\
315 \text { (5813), pp. } 769-770\end{array}$ & 28 \\
\hline $\begin{array}{l}\text { Ready to put metadata on the post- } 2015 \text { deve- } \\
\text { lopment agenda? Linking data publications to } \\
\text { responsible innovation and science diplomacy }\end{array}$ & \begin{tabular}{|l} 
Özdemir, V., \\
Kolker, E., Hotez, \\
P.J., (...), Srivastava, \\
S., Kickbusch, I. \\
\end{tabular} & 2014 & $\begin{array}{l}\text { Omics A Journal of } \\
\text { Integrative Biology } \\
18(1), \text { pp. } 1-9\end{array}$ & 25 \\
\hline $\begin{array}{l}\text { The modern phosphorus sustainability move- } \\
\text { ment: A profiling experiment }\end{array}$ & $\begin{array}{l}\text { Ulrich, A.E., } \\
\text { Schnug, E. }\end{array}$ & 2013 & $\begin{array}{c}\text { Sustainability } \\
\text { (Switzerland) } \\
5(11), \text { pp. } 4523-4545 \\
\end{array}$ & 18 \\
\hline $\begin{array}{c}\text { Science diplomacy: Investigating the perspective } \\
\text { of scholars on politics-science collaboration in } \\
\text { international affairs }\end{array}$ & Fähnrich, B. & 2017 & $\begin{array}{l}\text { Public Understanding of } \\
\text { Science } \\
26(6), \text { pp. } 688-703 \\
\end{array}$ & 17 \\
\hline $\begin{array}{l}\text { Innovation regimes based on collaborative and } \\
\text { global tinkering: Synthetic biology and nanotech- } \\
\text { nology in the hackerspaces }\end{array}$ & Kera, D. & 2014 & $\begin{array}{l}\text { Technology in Society } \\
37 \text { (1), pp. } 28-37\end{array}$ & 17 \\
\hline Biopolis: Asian Science in the Global Circuitry & Fischer, M.M.J. & 2013 & $\begin{array}{c}\text { Science, Technology and } \\
\text { Society } \\
18(3), \text { pp. } 379-404\end{array}$ & 16 \\
\hline $\begin{array}{l}\text { Science Diplomacy: Introduction to a Boundary } \\
\text { Problem }\end{array}$ & $\begin{array}{c}\text { Kaltofen, C., Acuto, } \\
\text { M. }\end{array}$ & 2018 & $\begin{array}{l}\text { Global Policy } \\
\text { 9, pp. 8-14 }\end{array}$ & 15 \\
\hline $\begin{array}{c}\text { Advancing science diplomacy: Indonesia and the } \\
\text { US Naval Medical Research Unit }\end{array}$ & Smith, F.L. & 2014 & $\begin{array}{l}\text { Social Studies of Science } \\
44(6), \text { pp. } 825-847\end{array}$ & 15 \\
\hline
\end{tabular}

Fuente: Scopus, febrero 9 de 2021. 
diplomacia científica (ver Science diplomacy: New day or false dawn? Editado por Lloyd Davis y Robert Patman, 2015), nuevas miradas de la misma desde otros países en desarrollo (e.g. Kera, 2014; Pickett et al., 2014; Fink et al., 2014), e incluso llamados a fortalecer la diplomacia científica por vía de la investigación e innovación responsable (RRI) (Kuhlmann et al., 2016) en la viabilización de los Objetivos de Desarrollo Sostenible, particularmente en Europa (Ver website https://www.s4d4c.eu/).

A partir de ese momento, el aumento en el número de documentos sobre diplomacia científica se intensificó, concretamente en el período de 2015 a 2020, como etapa reciente. Entre 2015 y 2016 se observa una menor cantidad de documentos, los cuales, sin embargo, expanden el universo empírico de análisis sobre la diplomacia científica con nuevos casos de estudio. Esta ampliación de casos de estudio conduce a un aumento mucho más marcado de documentos en 2017 y 2018, en particular con la publicación del número especial de la revista Global Policy (2018, vol. 9), en el que se aportan 12 artículos que ahondan en la diplomacia científica como 'problema de frontera' que suscita una 'tensión productiva' entre actores y prácticas de mundos sociales distintos, como lo son la ciencia y la diplomacia (Kaltofen y Akuto, 2018). El máximo de publicaciones anuales se encuentra en 2020, en donde destacan los artículos del fórum en The Hague Journal of Diplomacy (2020, vol.
15, núm. 3) y la colección en Humanities and Social Sciences Communications (2020, vol. 7 , núm. 1), los cuales buscan aportar a una conceptualización mucho más clara de la diplomacia científica, e incluso aportan algunas de las primeras lecturas críticas sobre el concepto. A la fecha en que se escribe este artículo (diciembre de 2020), una búsqueda de Google con la expresión "Science Diplomacy" arroja un total de casi 500 mil resultados, y para 2021 ya se anunciaban varias conferencias internacionales de gran reconocimiento en materia de políticas de CтеI, de Ciencia, Tecnología y Sociedad, y de Relaciones Internacionales, invitando a presentar ponencias académicas en la materia. Una de las mayores preocupaciones en la materia por el momento es su institucionalización y gobernanza, por lo que desde ya se han venido proponiendo protocolos al respecto (Aukes $e t$ al., 2020; Aukes, et al., 2021).

\subsection{Geografía de la producción de conocimiento sobre diplomacia científica}

En segundo lugar, como muestra la figura 4, es posible observar patrones de producción dominantes desde el Norte Global (EE. UU., Europa), con producción emergente en países emergentes del Sur Global (Brics, América Latina, África, Medio Oriente), según la afiliación institucional de los autores ${ }^{3}$.

Esta distribución obedece particularmente al criterio de búsqueda de literatura

\footnotetext{
3 Cabe aclarar que el país de la institución a la cual está afiliado el autor no necesariamente coincide con la nacionalidad del mismo. Esta afiliación institucional, y con esta el país de la misma, es reportada por cada autor dentro del artículo en cuestión.
} 


\section{Figura 4}

Distribución geográfica de la producción de conocimiento sobre diplomacia científica según número de documentos por país y según la afiliación institucional de autores $(N=167)$

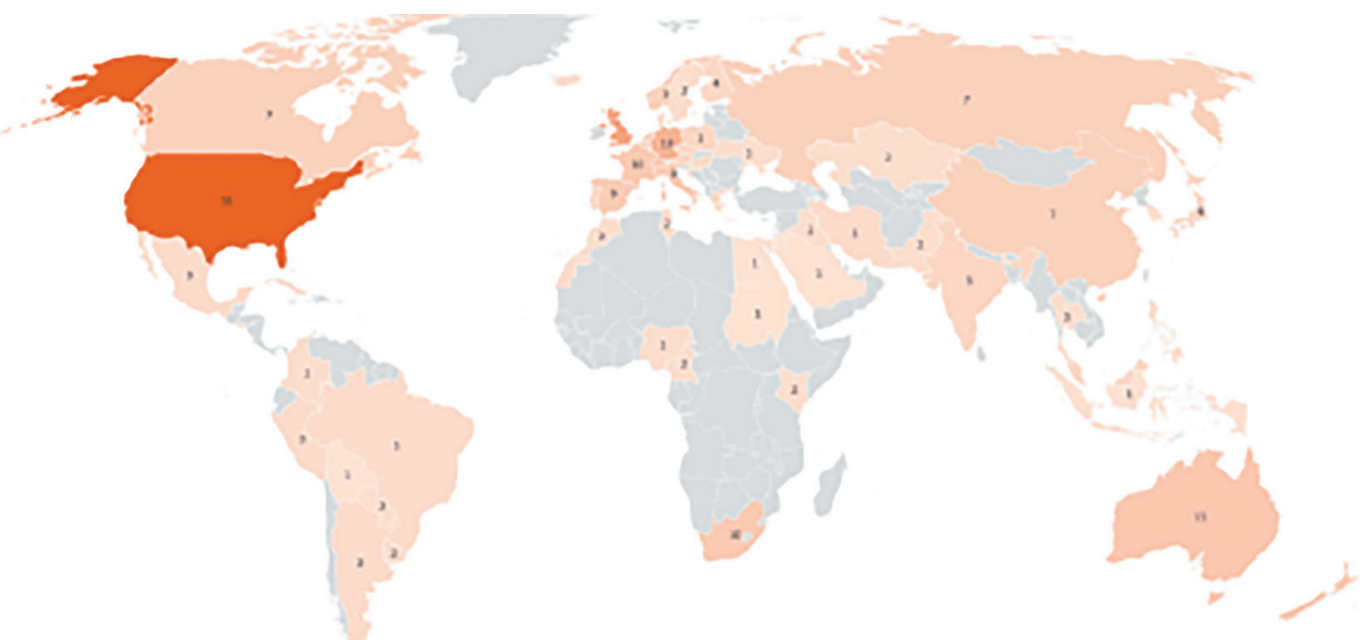

Fuente: Datos bibliográficos tomados de Scopus, según consulta en noviembre de 2020.

que usamos, en donde se consideraron documentos que incluían la expresión science diplomacy. Además de esto, cabe anotar que esta tendencia se inserta dentro de patrones de producción de conocimiento estructurales, en los que habitualmente el Sur Global presenta un rezago considerable asociado a sus capacidades diferenciadas de producción de conocimiento. Este asunto, que tiene que ver con lo que podría denominarse la 'geopolítica del conocimiento científico', es objeto de otras investigaciones. Por lo pronto, y para efectos del presente artículo, nos interesamos, en particular, por los aportes realizados desde la región latinoamericana, que se enmarcan en general dentro de trabajos colaborativos globa- les, con la participación de autores de diversas regiones del mundo.

Por ejemplo, para el caso de las potencias regionales como Brasil, se destaca la participación de autores en trabajos colaborativos donde se aborda la diplomacia científica en materia de seguridad y armas químicas (Forman et al., 2018; Timperley et al., 2018), con la participación de otros autores de países de la región como Cuba. Para el caso de este último, algunos han destacado el potencial de la diplomacia científica para mejorar las relaciones entre este país y Estados Unidos (McKinney, 2017). Algunos autores han contribuido, además, a discusiones sobre la necesidad de fortalecer los puentes entre la ciencia y la política para 
facilitar la incursión de los científicos en prácticas de diplomacia científica (Gore, Nichols y Lips, 2020), como lo han hecho también otros autores desde otras latitudes (Melchor, Elorza y Lacunza, 2020).

En el caso de Argentina, Malacalza (2017) analiza el rol de los científicos como actores políticos que inciden en la política exterior en materia de energía nuclear. De igual modo, desde este país se hacen contribuciones a casos internacionales como lo es el de Serbia, para el cual Pantovic y Michelini (2018) analizan el potencial de la diplomacia científica como mecanismo para la construcción de memoria histórica en contextos de transición hacia la paz.

Contribuciones desde El Salvador, Paraguay y Perú al rol de la diplomacia para fortalecer la salud basada en plantas (Giovani $e t$ al., 2020), para el caso de Bolivia se examinan los Clubes de Ciencia como ejemplo de colaboración entre naciones para fortalecer la educación científica (Carosso et al., 2019). En el caso de México, Wilder et al. (2020) destacan la importancia de la diplomacia científica en la gobernanza del agua de manera colaborativa entre ese país y Estados Unidos en la región fronteriza. Finalmente, destaca el análisis del rol que ha desempeñado en América Latina el Centro de Salud Global del Instituto Nacional de Cáncer de los Estados Unidos y sus estrategias de diplomacia científica con actores en la región, con contribuciones específicas desde México, Uruguay, Perú, Brasil y Argentina (French et al., 2018).

La producción en el caso de Colombia consiste, primero, en una reseña del libro Science diplomacy: New day or false dawn?, la cual, además de contribuir a la difusión de las discusiones en torno a la diplomacia científica que dicha obra propone, repasa algunos de los ejemplos latinoamericanos que pueden hacer de la diplomacia científica un campo de estudio fértil en la región (Bonilla, 2018). En segundo lugar, se encuentra el trabajo de Ramírez-Cabrales y Rueda (2020), quienes desde los estudios de seguridad y defensa analizan el rol de la diplomacia científica como mecanismo para viabilizar intereses nacionales en espacios marítimos, a partir del caso de una potencial zona 'colchón' en el caribe colombiano.

Otro hito importante en la materia lo marcó el Congreso Internacional "Gobernanza de la Ciencia y la Innovación. Hacia el desarrollo inclusivo", llevado a cabo entre los días 31 de julio y 1 y 2 de agosto de 2019 en Bogotá, organizado por la Red de Gobernanza y Gestión del Conocimiento, la Ciencia, la Tecnología y la Innovación (RedGCTI), el cual incluyó una mesa sobre diplomacia científica en la que los participantes discutieron sobre investigaciones en curso, relacionadas con la integración regional en materia de política espacial, la contribución de la diplomacia en la construcción de capacidades científicas en países de Centroamérica, la internacionalización de la investigación e innovación universitaria, la relación entre el desarrollo y la diplomacia científica desde los estudios sociales de la ciencia, la investigación e innovación, responsables en materia de bioeconomía en América Latina, entre otros (Ordóñez y Centeno, 2019).

Por último, recientemente se aprobó, en Colombia, la primera disertación doctoral en la materia, de María Piedad Villaveces, del Doctorado en Estudios Políticos de la Facultad de Finanzas, Gobierno y Relaciones 
Internacionales, de la Universidad Externado de Colombia, quien aborda las formas en que la diplomacia científica se acomoda como práctica en la institucionalidad colombiana en apego al legalismo plural.

\subsection{Campos disciplinares y temas recurrentes en la producción de conocimiento sobre diplomacia científica}

La producción sobre diplomacia científica se desarrolla desde tres grandes cuerpos disciplinares: primero, se concentra (50\%) en ciencias sociales, ambientales y artes y humanidades. Luego se destaca el campo de la economía, administración y negocios (38\%). Finalmente, destacan las ingenierías y ciencias naturales y exactas (18\%). (Ver figura 5.)

Figura 5

\section{Áreas del conocimiento desde las que se produce conocimiento sobre diplomacia científica, número de documentos por área $(\mathrm{N}=167)$}

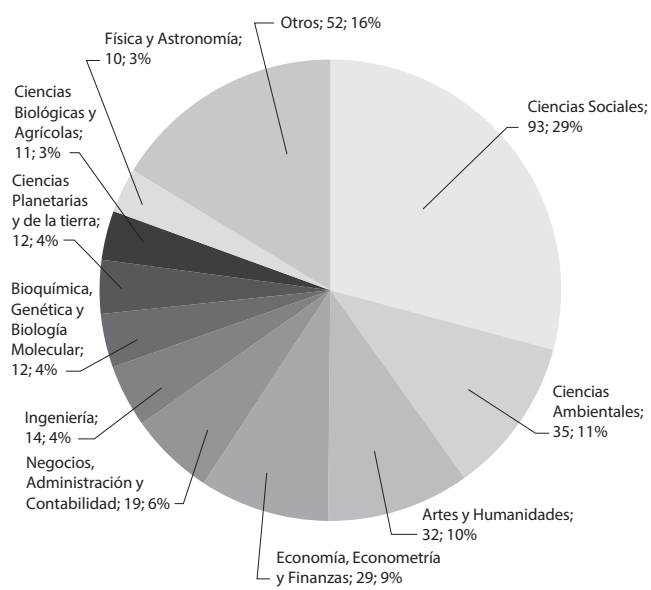

Fuente: Datos bibliográficos tomados de Scopus, según consulta en noviembre de 2020
Ahora bien, interesa de manera particular identificar cuáles son los temas recurrentes en las discusiones sobre diplomacia científica. La figura 6 ilustra el mapa de calor de palabras clave de los documentos sobre diplomacia científica identificados, en donde el tamaño de las palabras indica su frecuencia y su posición expresa su concurrencia con otras expresiones. Como es natural, science diplomacy es el término con mayor frecuencia y centralidad, seguido de nociones como international cooperation, United States, diplomacy, diplomatic relations y foreign policy (omitidas en la gráfica por ocupar un área muy grande que invisibiliza otra información de interés), que expresan el arraigo de la diplomacia científica en la disciplina de las relaciones internacionales. Por su parte, algunas expresiones en el mapa como science policy, science and technology, research y scientist (también omitidas por la misma razón) sugieren que la diplomacia científica tiende a diversificarse en los estudios de ciencia, tecnología e innovación, en donde existe una creciente preocupación por el análisis y la conceptualización de esta.

Destaca en el mapa expresiones emergentes como climate change, public health o environmental policy, que representan los retos típicos en torno a los cuales la diplomacia científica adquiere un carácter instrumental como mecanismo para su abordaje (área en rojo). La región periférica del mapa ilustra los tópicos específicos y sectoriales que concurren en las preocupaciones sobre diplomacia científica en estos documentos, los cuales incluyen expresiones propias de asuntos de salud pública, medio ambiente, armas nucleares y químicas, agua, geopolítica, entre otros (área en amari- 
Figura 6

Mapa de calor de palabras clave en los documentos sobre diplomacia científica

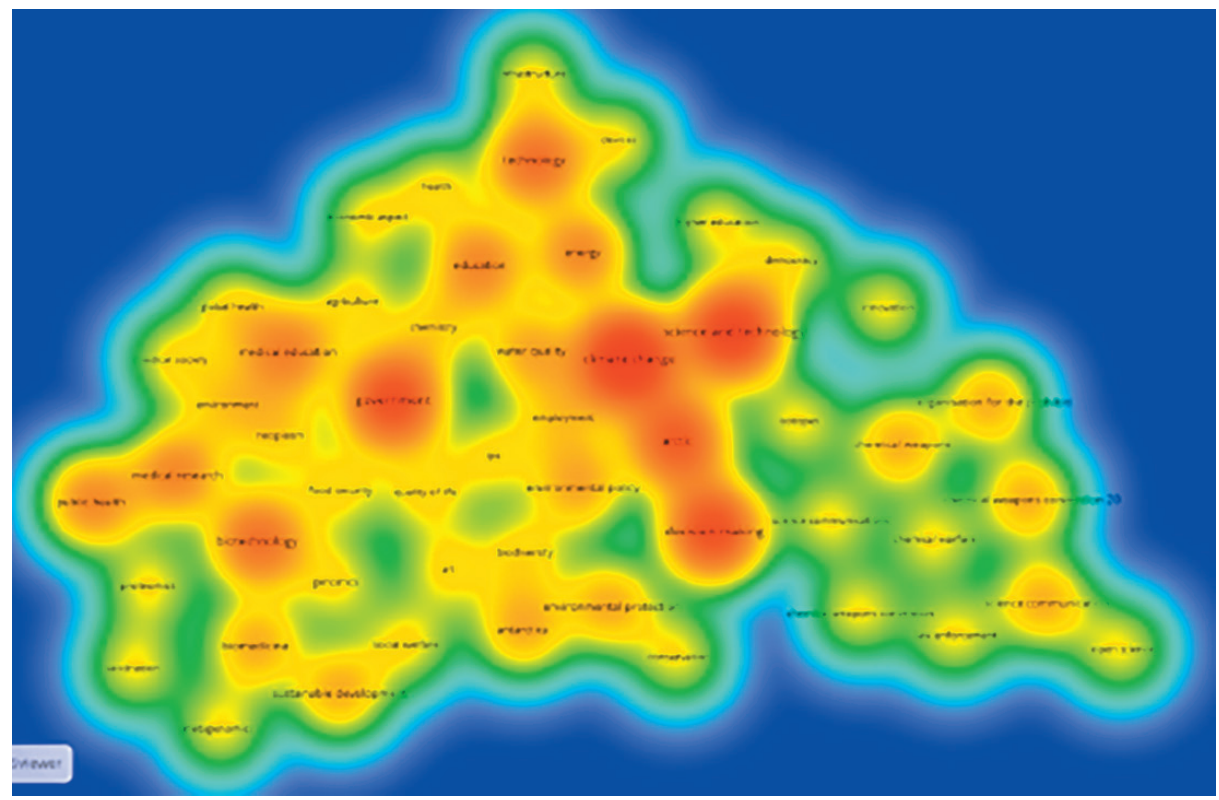

Fuente: Datos bibliográficos tomados de Scopus.

llo). Asimismo, expresiones como governmenty decision making reafirman el rol que desempeña la diplomacia científica como mecanismo de apoyo para el ejercicio del gobierno y la toma de decisiones de política exterior basadas en evidencia científica. Esto cobra especial relevancia en el contexto del asesoramiento científico para el abordaje de retos globales como lo es el Covid-19.

Lo anterior sugiere que se trata entonces de discusiones que, desde el punto de vista disciplinar, se realizan de manera predominante desde la intersección entre campos como las relaciones internacionales y los estudios de ciencia, tecnología e innovación, y cuya base empírica y objetos analíticos se encuentran con frecuencia en los asuntos ambientales, en particular por los retos que ocupan a la diplomacia científica, en donde se destaca el cambio climático, la gobernanza energética, la biodiversidad, la gobernanza del agua, la protección de ecosistema marinos, las dinámicas de poder e investigación en torno al Ártico, entre otros. Se trata, en suma, de una reflexión de vocación interdisciplinaria e intersectorial.

\section{EXPERIENCIAS INTERNACIONALES DE DIPLOMACIA CIENTÍFICA}

En esta sección repasamos algunas experiencias internacionales para identificar algunos elementos que ofrezcan respuesta sobre cuáles son las condiciones necesarias para el desarrollo de la diplomacia científica en países como Co- 
lombia. La Unión Europea ha sido pionera en el impulso de políticas y programas orientados a promover y consolidar la diplomacia científica. Algunos de estos programas, financiados con recursos del programa Horizonte 2020, Science with and for Society (SwafS), incluyen proyectos como Using Science for/in Diplomacy for addressing global Challenges o S4D4C, en los que un amplio consorcio de actores, entre gobiernos y universidades, convergen para desarrollar, por ejemplo, trabajos de investigación sobre diplomacia científica y capacitaciones a profesionales para desenvolverse mejor en la arena política y diplomática.

Estos esfuerzos condujeron, en diciembre de 2018, a la primera Conferencia Global sobre Diplomacia Científica, de la cual resultó la 'Declaración de Madrid sobre la Diplomacia Científica', suscrita en febrero de 2019 por alrededor de 150 académicos y diplomáticos de diversos países. En esta se proclama una visión compartida sobre la diplomacia científica de cara al futuro, y se destacan algunos de los beneficios de la misma de cara al abordaje de los retos globales del siglo XxI. Algunos de estos beneficios son (s4D4C, 2019):

- Facilitar la identificación de desafíos globales comunes, siendo un punto de partida para la ciencia y la tecnología.

- Relaciones internacionales más productivas y sostenibles a nivel multilateral y bilateral.

- Mejores políticas exteriores basadas en evidencia y respaldadas por la ciencia y la tecnología, con el objetivo de lograr acuerdos, tratados y políticas internacionales sustantivas y resistentes.
- Mejores condiciones para la actividad científica, gracias al aporte de las agendas de política exterior. La diplomacia, con el apoyo de la comunidad científica, tiene un papel particular que desempeñar en la implementación de iniciativas y proyectos científicos más amplios (por ejemplo, infraestructuras de investigación, programas conjuntos, etc.).

- Interfaces mejoradas entre ciencia y políticas públicas, en donde la diplomacia científica puede contribuir a eliminar las barreras culturales, sectoriales y de conocimiento entre diferentes actores, como los responsables de la formulación de políticas, los investigadores, los organismos diplomáticos y la sociedad civil.

La misma declaración señala algunos de los principios orientadores para el fomento de la diplomacia científica alrededor del mundo, como lo son (s4D4C, 2019):

- Garantizar valor para los ciudadanos.

- Fomentar la diversidad metodológica.

- Procurar impactos demostrables.

- Basar las iniciativas en evidencia.

- Fomentar la colaboración e inclusión.

- Contribuir a la creación de capacidades.

- Respetar la independencia de la ciencia.

Con base en estos principios orientadores, es importante resaltar que los países y grupos de académicos, se han diversificado y constituido en diásporas de conocimiento para promover la diplomacia científica como una disciplina universal y necesaria. Si bien los agentes de estas redes suelen ejercer esta disciplina de forma individual, la creación de redes ha permitido el desarrollo de espacios de diplomacia científica para enfoques locales, nacionales, regionales o globales. Algunos 
ejemplos de redes de diplomacia científica en distintos niveles se presentan en la figura 7 .

A manera de ejemplo, la German Academic Internacional Network (GAIN), es una red nacional alemana de académicos e instituciones en el exterior que buscan la comunicación científica por medio de científicos e investigadores científicos, quienes comparten conocimientos con líderes en Estados Unidos y Canadá. Gracias a esta red y a la interoperabilidad entre sus miembros, se han venido trazando líneas de acción y construcción de oportunidades de movilidad y cooperación transatlánticas para capacitar y proyectar futuros profesionales, diplomáticos y científicos en este espacio de interacción de ambas ciencias.

Se destaca también el Panel Intergubernamental sobre el Cambio Climático (IPCC), que corresponde a un gran ejemplo de la relación de estas dos disciplinas de forma global, donde confluye lo que Haas denominaría una "comunidad epistémica internacional” (Haas, 1992) o Sabatier denominaría "Advocacy Coalitions" (Sabatier, 1988). Es un grupo intergubernamental (multi stakeholder) que durante varios años ha facilitado la evaluación de los conocimientos científicos, técnicos y socioeconómicos sobre el cambio climático. Sus informes han contribuido a plantear importantes estamentos de desarrollo sostenible, gestión de riesgo y apreciaciones de cambio climático para que los gobiernos generen respuestas inmediatas mediante la adaptación y mitigación. Sin embargo, este órgano intergubernamental ha requerido del involucramiento de un gran número de actores e instituciones para ofrecer, desde el seno de la visión científica, las repercusiones medioambientales y socioeconómicas sobre la vida de los países para así adoptar decisiones pertinentes y equilibradas.

Figura 7

\section{Redes de la diplomacia científica}
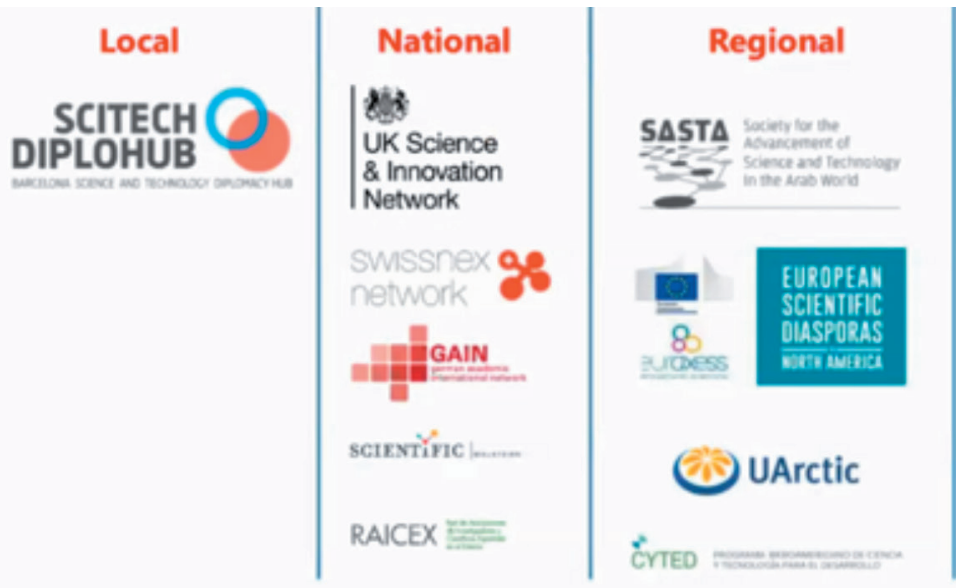

\section{Global}

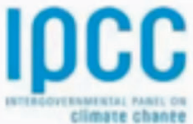

climute shante

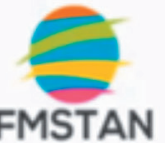

SCIENCE

Fuente: Lacunza (2020); Elorza, Melchor y Lacunza (2020). 
Por su parte, en América Latina la experiencia de Brasil es ilustrativa en materia de programas de impulso a la diplomacia científica. Tal es el caso del Marco de São Paulo para la Diplomacia de la Innovación, con el cual se busca integrar los mercados de ese país con empresas tecnológicas, con el fin de fomentar la inversión extranjera en investigación y desarrollo, así como movilizar diásporas de talento humano altamente cualificado para contar con transferencia tecnológica internacional.

Ahora bien, algunos de los retos para la región latinoamericana en la materia tienen que ver con el manejo del idioma inglés por parte de académicos y diplomáticos para insertarse en procesos de diplomacia global, así como las barreras para la internacionalización de la academia y las empresas para participar en cadenas de valor de escala global. Esto explica, en alguna medida, la lenta inserción de la región latinoamericana en prácticas sistemáticas de diplomacia científica impulsadas desde los gobiernos en el marco de la política exterior donde, en muchas ocasiones, los representantes nacionales son más seguidores que proponentes de temas de la agenda internacional.

En el caso chileno se destaca el proyecto astronómico Atacama Large Millimeter Array (Alma), producto de la colaboración entre organizaciones científicas en la Unión Europea, Chile, Estados Unidos, Canadá, Corea, Japón y Taiwán. Se trata de un telescopio formado por un sistema de antenas de alta precisión que permite observar la formación de distintos cuerpos celestes. Como se menciona en el portal web del proyecto, este busca estudiar la formación de estrellas, las nubes moleculares y el universo temprano para conocer los orígenes cósmicos y la información necesaria sobre el sistema solar ${ }^{4}$. Este proyecto se inscribe dentro de una estrategia de diplomacia científica más amplia del gobierno chileno que busca impulsar la colaboración científica internacional en el campo astronómico y el fortalecimiento de las capacidades científicas del país (Rodríguez García-Huidobro, 2017).

\section{CONDICIONES PARA LA VIABILIDAD DE LA DIPLOMACIA CIENTÍFICA: PERSPECTIVAS PARA COLOMBIA}

Promover una estrategia de diplomacia científica en Colombia debería propender por fortalecer, aprovechar, acceder y posicionar las capacidades en ciencia, tecnología e innovación que requiere el país según sus especificidades, es decir, definir de manera más clara lo que tiene en abundancia (biodiversidad, creatividad, turismo, etc.) y lo que le falta o necesita (también 'en abundancia', como seguridad, equidad, productividad empresarial, eficiencia administrativa, etc.). Actualmente, la institucionalidad colombiana cuenta con algunos instrumentos para el desarrollo de lo anterior. Por ejemplo, a las Oficinas Consulares Honorarias, con las que cuenta el país en el

\footnotetext{
4 Disponible en https://www.almaobservatory.org/es/sobre-alma/ <?> Disponible en https://www.almaobservatory. org/es/sobre-alma/
} 
exterior, se les atribuye el fomento de relaciones científicas con otros países, así como obtener información al respecto de la evolución en dichas relaciones 5 . Asimismo, el Ministerio de сте cuenta con una oficina de internacionalización cuyo propósito es:

generar y fortalecer alianzas entre los actores del Sistema Nacional de стег y actores internacionales estratégicos, con un equipo de trabajo organizado por escritorios geográficos que desarrollan actividades para: 1) Promover el avance de la стег mediante la participación en escenarios internacionales estratégicos; 2) Promover la circulación de conocimientos y prácticas innovadoras en un escenario global; y 3 ) Gestionar recursos técnicos y financieros de cooperación internacional en cтег (MinCiencias, s.f.).

Otras experiencias como la Red Colombiana de Investigadores en el Exterior (Red Caldas) (1990), el Programa de Diplomacia Científica (2003) del entonces Colciencias, o la participación de Colciencias en el Consorcio AL-INVEST III (2006) ilustran los esfuerzos realizados por distintos gobiernos de Colombia por insertar a la ciencia del país en redes y cadenas de generación de conocimiento a nivel global (Isaza, 2020).

Sin embargo, dichos esfuerzos no han logrado institucionalizarse para un desarrollo permanente y sistemático, debido a la ausencia de políticas de diplomacia científica de largo plazo que viabilicen prácticas de colaboración con otros países para promover el avance científico y el abordaje de retos compartidos con soluciones basadas en innovación.

Algunos sectores académicos y gubernamentales llaman la atención sobre la necesidad de retomar dichas experiencias con el propósito de establecer políticas de diplomacia científica que abran puertas para la ciencia colombiana a nivel global. En ese sentido, desde el gobierno se han fomentado algunas condiciones iniciales que resultan necesarias para tal propósito. Por ejemplo, el discurso gubernamental en ciencia y tecnología es creciente, como lo manifiesta su inclusión en un capítulo específico del actual Plan Nacional de Desarrollo 2018-2022. Asimismo, la transformación de Colciencias en Ministerio y la creación de la Misión Internacional de Sabios hablan de algunos intentos por fortalecer la gobernanza de la Cтеi en el país.

Desde el Ministerio de Relaciones Exteriores se ha reconocido la necesidad de articular dichos esfuerzos con prácticas formales de diplomacia científica, sobre todo frente a los retos que implica la búsqueda de una vacuna para el Covid-19 en la arena internacional, lo cual requiere de una articulación clara entre la Cancillería, el Ministerio de CTeI y el Ministerio de Salud para tal propósito.

La búsqueda de soluciones a la pandemia del Covid-19 ha puesto de relieve múltiples mecanismos de interacción científica en salud entre países, ya sea de manera multilateral, co-

5 Ver Decreto 952 de 2014 "por medio del cual se reglamenta el servicio consular honorario de Colombia; la apertura y funcionamiento de las oficinas consulares honorarias y se dictan otras disposiciones sobre la materia”. 
mo lo es la plataforma Covax, o bilateral. En relación con esto último, es destacable cómo dicho contexto ha obligado tender puentes de colaboración, incluso entre gobiernos que sostienen actualmente relaciones diplomáticas frágiles como es el caso de Colombia y Venezuela, quienes enfrentan retos compartidos y que han logrado acercarse para intercambiar información que contribuya al abordaje de la pandemia en la frontera, con la mediación de la Organización Panamericana de la Salud (ops) ${ }^{6}$. Es así como la diplomacia científica en ámbitos sectoriales diversos, y con la participación de distintos actores como facilitadores, puede contribuir al abordaje de grandes retos regionales y globales.

Los anteriores ejemplos ilustran cómo la diplomacia científica, en tanto concepto 'sombrilla', incluye y se intersecta con una serie de prácticas que ponen de relieve la interfaz ciencia-diplomacia, y dentro de las cuales pueden encontrarse ámbitos de práctica consolidados como lo son la diplomacia en salud (bealth diplomacy), la diplomacia climática (climate diplomacy), entre otras acciones de política exterior que destacan la importancia de la ciencia, la tecnología y la innovación. En otras palabras, otros tipos de diplomacia como la climática o en salud, pueden incluir prácticas de diplomacia científica, en tanto el rol del conocimiento resulta central para informar la toma de decisiones en esos ámbitos sectoriales.
Para que esta nueva 'ola' de interés por la diplomacia científica no sea una simple 'moda' pasajera, se hace necesario su aprovechamiento, tanto en cuanto a sus tres formatos discutidos (diplomacia para la ciencia, ciencia para la diplomacia y ciencia en la diplomacia) como su carácter estratégico en términos de su utilidad para influir en las agendas globales, facilitar el acceso a la cTeI internacional y posicionar la стег nacional en el exterior; propósitos para los cuales la diplomacia científica debería ser concebida, al menos en gran medida, como una extensión de las políticas públicas nacionales en reconocimiento del papel protagónico de la CTeI en la sociedad, tanto como fuente de soluciones como fuentes de potenciales problemas.

Esto implica también tener en cuenta la dimensión política (politics) en una eventual política pública (policy) de diplomacia científica, que garantice su viabilidad y que permita resolver eventuales tensiones diplomáticas. Más aún, se hace necesario ahondar en las dinámicas tanto de colaboración como de competencia que tienen lugar en el ámbito de la diplomacia científica (Ruffini, 2020). Esta consideración cobra relevancia frente a casos recientes, como lo fue la preocupación expresada por la Embajada de Estados Unidos en Colombia ante una eventual licitación del Servicio Nacional de Aprendizaje (Sena) en materia de modernización tecnológica que,

6 Ver: "A través de ops, Colombia intercambia información sanitaria con Venezuela", Ministerio de Salud. Boletín de Prensa No. 076, 17/03/2020. Disponible en https:/www.minsalud.gov.co/Paginas/A-traves-de-ops-Colombiaintercambia-informacion-sanitaria-con-Venezuela.aspx 
presuntamente, podría beneficiar a la multinacional china Huawei ${ }^{7}$. Esta situación se presentó en el marco de la denominada 'guerra comercial' entre Estados Unidos y China, lo que demuestra que las relaciones entre otros países pueden tener una incidencia en la toma de decisiones del gobierno colombiano, ante lo cual una diplomacia científica y tecnológica podría contribuir a un mejor abordaje de dichas controversias sin que se vean afectados los asuntos internos de Colombia.

Ahora bien, consolidar una política de diplomacia científica para Colombia implica, ante todo, invertir más en CTeI en el país (menos del 0,4\% del pIB se destina a I+D); promover su difusión a todo nivel (aumentar el 'alfabetismo científico y tecnológico' en la población); fomentar la articulación y coordinación interdisciplinaria entre la academia y el mercado laboral para evitar la denominada fuga de cerebros ${ }^{8}$; repensar y formular un modelo de desarrollo para Colombia que atraiga la inversión extranjera para la investigación y la innovación; y fomentar una interacción diversa y fluida entre múltiples actores para el abordaje de retos sociales, económicos y ambientales. Asimismo, se requieren directrices claras y de alto nivel para consolidar una capacidad institucional y organizacional que facilite la consecución de recursos para la investigación y la innovación a nivel internacional.

\section{CONCLUSIONES}

La diplomacia cientifica es un concepto emergente que busca tender puentes entre la ciencia, las políticas públicas y la diplomacia para facilitar el abordaje de grandes retos globales a través de la colaboración entre gobiernos y actores de distintos países. En efecto, el rápido avance tecnológico aunado a fenómenos como la globalización y la interrelación más estrecha entre países, han derivado en grandes retos globales cuyo origen, en muchos casos, tiene lugar en territorios específicos llegando a afectar a otros: la pandemia del Covid-19, el cambio climático, las crisis migratorias, el hambre y la desigualdad, entre otros. El abordaje de dichas problemáticas implica la necesaria colaboración inter-estatal, ya no solo en el plano político, sino también en el plano científico y tecnológico, propendiendo por soluciones inclusivas, sostenibles y efectivas basadas en conocimiento.

En ese contexto, el presente artículo repasa las principales conceptualizaciones de la diplomacia científica, examina algunos casos internacionales y reflexiona sobre sus perspec-

\footnotetext{
7 Ver: "Embajada preocupada por licitación del Sena que beneficiaría a Huawei”, W Radio. 22/05/2019. Disponible en https://www.wradio.com.co/noticias/actualidad/embajada-preocupada-por-licitacion-del-sena-que-beneficiaria-ahuawei/20190522/nota/3905734.aspx

$8 \quad \mathrm{Al}$ respecto de la diáspora científica y de cómo vincular al personal altamente cualificado en asuntos de política desde el extranjero, ver Meyer y Brown, 1999; Saxenian, 2006; Riordan, 2016; Elorza, 2017. Agradecemos a los evaluadores de este artículo por recomendar dichos trabajos que ilustrarán con mayor detalle al lector interesado en la diáspora científica.
} 
tivas en Colombia, con el propósito de esclarecer los alcances del concepto y de contribuir a su difusión como aproximación relevante al abordaje de retos mundiales. Se trata de un concepto que, como otros en relaciones internacionales, obliga a repensar la tradicional concepción westfaliana Estado-Nación y las relaciones entre este y otros actores, en donde la ciencia cobra relevancia como vía para el desarrollo sostenible e inclusivo. Este concepto implica el acercamiento entre el campo de la ciencia y la diplomacia, tradicionalmente pensados como estamentos separados, y cuya interacción puede manifestarse de distintas formas, bien sea como ciencia en la diplomacia, la diplomacia para la ciencia o la ciencia para la diplomacia. Para el caso de Colombia, la diplomacia científica se trata no solo del abordaje de retos globales sino, también, de retos nacionales, regionales y locales, niveles sobre los que las dinámicas contemporáneas globales tienen incidencia. Asimismo, la diplomacia científica implica interacciones entre diversos actores, no solo con el propósito de cooperar sino también, en algunos casos, de competir por una posición que les permita viabilizar sus intereses.

Ahora bien, si bien este representa múltiples oportunidades frente a los retos del mundo globalizado, resulta necesario mencionar algunas de sus limitaciones para dar alcance al concepto de diplomacia científica. Para autores como Rungius \& Flink (2020) y Flink (2020), en primer lugar, es necesario distinguir la diplomacia científica de otras nociones relacionadas como pueden ser las políticas internacionales de CTeI, u otros tipos de diplomacia como la climática o en salud.
En ese sentido resulta necesario avanzar en la conceptualización de dichas aproximaciones, así como construir marcos analíticos que permitan diferenciar los alcances de los mismos.

En segundo lugar, a los discursos gubernamentales sobre diplomacia científica subyace un entendimiento 'solucionista' y 'positivo' de la ciencia, impulsado por discursos de promotores de la misma desde agencias estatales y diplomáticas que incursionan en la práctica de la diplomacia científica (Flink, 2020). En otras palabras, puede que la ciencia no represente en estricto sentido soluciones para determinados problemas, donde la diplomacia científica sea mucho menos una 'panacea'. Por el contrario, puede que la ciencia y la tecnología incluso generen nuevas problemáticas y aumenten las brechas, donde no se inserten dentro de agendas de desarrollo bien concebidas, lo que contrasta con los intereses de diversos actores del sistema internacional.

En ese sentido, debe considerarse además que la ciencia no puede dar solución a todos los problemas si no se cuenta con entornos habilitantes para tal propósito, y si no se desarrollan soluciones de manera inclusiva. Lejos de instrumentalizar a la ciencia, se debe pensar en una diplomacia científica responsable e inclusiva, que considere los intereses de diversos actores y propenda por soluciones por fuera de lógicas de 'suma cero'. Asimismo, se requiere también un abordaje crítico de la diplomacia científica, de modo que se pueda tener presente los posibles riesgos de la misma, sobre todo si se considera que las prácticas científicas y diplomáticas también pueden acarrear externalidades negativas, excluyentes, donde hay ganadores y perdedores según el contexto. 
En este artículo identificamos que la producción de nuevo conocimiento sobre diplomacia científica ha evolucionado rápidamente durante los últimos años, con un especial impulso de emprendedores institucionales y practitioners de política exterior. Se trata, sin embargo, de un concepto que no es nuevo y que ha tenido algún grado de discusión desde finales del siglo xx. La discusión al respecto es aún emergente para el caso de América Latina, en donde algunos autores desde instituciones de la región han realizado aportes en el marco de proyectos colaborativos de escala global. Los principales temas asociados a la diplomacia científica muestran el arraigo de esta en el campo de las relaciones internacionales, así como su diversificación en los estudios de ciencia, tecnología e innovación. Temas como el cambio climático, la salud pública y las políticas ambientales emergen como retos típicos abordados por la diplomacia científica. Identificamos también la relevancia que en este contexto cobra la diplomacia científica como mecanismo de apoyo al ejercicio del gobierno y la toma de decisiones de política exterior basada en evidencia científica.

Futuras investigaciones deberán continuar monitoreando el avance en el conocimiento sobre el tema, tanto desde el estamento científico como institucional en idiomas distintos al inglés. Esto considerando que se trata de un tema que tiende a cobrar fuerza entre el público hispanoparlante, tanto académicos como practitioners de la diplomacia científica. Si bien este artículo ofrece una mirada a la producción de nuevo conocimiento sobre el tema, futuros mapeos deberán incluir la evolución de la discusión desde la literatura gris, en donde se establezca cómo los documentos de política conceptualizan y operacionalizan la diplomacia científica.

La diplomacia científica puede ser entonces una estrategia que contribuya al fortalecimiento de la capacidad científica y tecnológica de Colombia, así como a un mejor aprovechamiento de los recursos con que cuenta el país en materia de biodiversidad, conocimiento y creatividad. Asimismo, con estos atributos el país puede contribuir a la producción de conocimiento de frontera global, propendiendo por prácticas científicas justas en las que los beneficios de la investigación se distribuyan de manera equitativa entre los distintos actores involucrados, sobre todo a nivel territorial en donde diversos proyectos de investigación tienen lugar, pero que no generan retribuciones a las comunidades que apoyan su desarrollo. En ese contexto, Colombia tiene una oportunidad valiosa para fortalecer su posición en el escenario latinoamericano y global, en pro de una sociedad más justa y de un desarrollo sostenible e inclusivo basado en el conocimiento.

\section{RECONOCIMIENTOS}

El artículo se nutre de las discusiones que tuvieron lugar en un evento pionero sobre la diplomacia científica organizado por la Facultad de Finanzas, Gobierno y Relaciones Internacionales (Figri) de la Universidad Externado de Colombia el pasado 16 de julio de 2020. El evento, que se desarrolló de manera virtual, contó con la participación de panelistas nacionales e internacionales expertos en el tema, quienes intercambiaron puntos de vista sobre las experiencias internacionales de la 
diplomacia científica y sus perspectivas para Colombia.

Dentro de los panelistas internacionales se encontraban Lorenzo Melchor y Marga Gual Soler, ambos miembros del proyecto S4D4C de la Unión Europea'; y Pedro Ivo Ferraz da Silva, secretario y jefe de Ciencia, Tecnología e Innovación de la Embajada de Brasil en Nueva Delhi, India. Por su parte, los participantes nacionales fueron María Piedad Villaveces, directora ejecutiva de la Asociación Colombiana para el Avance de la Ciencia (Acac); y Lucas Gómez, director de asuntos económicos, sociales y ambientales del Ministerio de Relaciones Exteriores de la Cancillería de Colombia. Asimismo, se contó con la participación de docentes e investigadores de Figri, como Martha Ardila, coordinadora del Observatorio de Análisis de los Sistemas Internacionales (Oasis); María Teresa Aya, coordinadora de la Maestría en Asuntos Internacionales; Soraya Caro, directora del Centro de Estudios sobre India Contemporánea (Cesicam); Rafael Piñeros, coordinador del Área de Relaciones Internacionales de la Facultad; Paula Ruiz, directora de la Escuela de Relaciones Internacionales; y Gonzalo Ordóñez-Matamoros, director del Centro de Investigaciones y Proyectos Especiales (Cipe), quien moderó el webinar y es también miembro del proyecto s4D4C.

Agradecemos, de manera especial, a los pares evaluadores del presente artículo por sus importantes comentarios y sugerencias que enriquecieron el contenido de la reflexión que aquí se presenta.

\section{REFERENCIAS}

Aukes, E.; Wilsdon, J.; Ordóñez-Matamoros, G. and Kuhlmann, S. (2021). Global resilience through knowledge-based cooperation: A New Protocol for Science Diplomacy. S4D4C Project. Disponible en https://www.s4d4c.eu/the-new-sciencediplomacy-protocol/

Aukes, E.; Ebrahimi, S.H.; Ordóñez-Matamoros, G. and Kuhlmann, S. (2020). Towards effective science diplomacy practice. s4D4C Policy Brief, No. 2. s4D4C (Vienna). Disponible en https:// www.s4d4c.eu/wp-content/uploads/2020/01/ s4D4C-Towards-effective-science-diplomacypractice.pdf.

Bonilla Aranzales, J. K. (2018). Science Diplomacy: New day or false dawn. Análisis Politico, 31(94), 209-212. Doi: https://doi.org/10.15446/anpol. v31n94.78311

Carosso, G. A.; Ferreira, L. M. R. and Mostajo-Radji, M. A. (2019) Developing Brains, Developing Nations: Can Scientists Be Effective Non-state Diplomats? Front. Educ. 4:95. Doi: 10.3389/ feduc.2019.00095

Copeland, D. (2016). Science Diplomacy. En C. Constantinou, P. Kerr \& P. Sharp (Edits.), Sage Handbook of Diplomacy (pp. 628-641). London: Sage Publications.

Elorza, A.; Melchor, L.; Orts-Gil, G.; Gracia, C.; Lacunza, I.; Izquierdo, B. and Fernández-Vera, J.

9 Ver más sobre el proyecto 54D4C (Using Science for/in Diplomacy for addressing global Challenges) en https://www. s4d4c.eu/ 
I. (2017). Spanish Science Diplomacy: A Global and Collaborative Bottom-Up Approach, Science \& Diplomacy, vol. 6, No. 1.

Elorza, A.; Melchor, L. and Lacunza, I. (2020). Who Are the Science Diplomacy Stakeholders? In s4D4C European Science Diplomacy Online Course, Module 3, Vienna: 54D4C. Disponible en https:// www.s4d4c.eu/european-science- diplomacyonline-course/

Fedoroff, N. (2009). Science Diplomacy in the 21st Century. Cell, 136 (1), 9-11.

Flink, T. (2020). The sensationalist discourse of science diplomacy: A critical reflection. The Hague Journal of Diplomacy, 15 (3), pp. 359-370

Flink, T. (03/09/2020). Blog Post | Actions and Lofty Promises of Science Diplomacy. Obtenido de https://www.universiteitleiden.nl/hjd/ news/2020/blog-post---actions-and-lofty-promises-of-science-diplomacy

Flink, T. \& Schreiterer, U. (2009). Aufgabenkritische Analyse deutscher Außenwissenschaftspolitik (AWP) in sechs ausgewählten Zielländern. WZB: Abschlussbericht.

Forman, J. E. et al. (2018). Innovative technologies for chemical security. Pure and Applied Chemistry, 90 (10), pp. 1647-1670.

French, S. et al. (2018). Perspectives on Strengthening Cancer Research and Control in Latin America Through Partnerships and Diplomacy: Experience of the National Cancer Institute's Center for Global Health. Journal of Global Oncology, vol. 4. Doi: 10.1200/JGO.17.00149

Rodríguez García-Huidobro, G. (2017). Chile: Global Astronomical Platform and Opportunity for Diplomacy, Science \& Diplomacy, vol. 6, No. 2.

Giovani, B.; Blümel, S.; Lopian, R. et al. (2020). Science diplomacy for plant health. Nat. Plants 6, 902-905
Gluckman, P.D.; Turekian, V.; Grimes, R.W. and Kishi, T. (2017). Science Diplomacy: A Pragmatic Perspective from the Inside, Science \& Diplomacy, vol. 6, No. 4.

Gore, M. L.; Nichols, E. S. and Lips, K. R. (2020). Preparing scientists for science diplomacy requires new science policy bridges. The Hague Journal of Diplomacy, 15 (3), pp. 424-434.

Haas, P. M. (1992). Epistemic communities and international policy coordination. International Organization, 46 (1), 1-35.

Harris, P. G. (Edited) (2009). Climate change in environmental foreign policy: Science, diplomacy, and politics. Climate Change and Foreign Policy: Case Studies from East to West, pp. 1-17. Routledge, ISBN: 0203881400; 978-020388140-8. Doi: $10.4324 / 9780203881408$

Isaza, J. P. (2020). Breve repaso del contexto institucional de la diplomacia científica, tecnológica y de innovación en Colombia 2004-2006. Innovación \& Ciencia, xxviI (2). Obtenido de https:// innovacionyciencia.com/articulos_cientificos/ breve-repaso-del-contexto-institucional-de-la-diplomacia-cientifica-tecnologica-y-de-innovacionen-colombia-2004-2006

Juma, C. (2002). Biotechnology and international relations: Forging new strategic partnerships. International Journal of Biotechnology, 4 (2-3), pp. 115-128.

Kaltofen, C. and Akuto, M. (2018). Science Diplomacy: Introduction to a Boundary Problem, Global Policy 9, pp. 8-14

Kera, D. (2014). Innovation regimes based on collaborative and global tinkering: Synthetic biology and nanotechnology in the hackerspaces. Technology in Society, vol. 37, pp. 28-37.

Kuhlmann, S.; Edler, J.; Ordóńez-Matamoros, G.; Randles, S.; Walhout, B.; Gough, C. \& Lindner, 
R. (2016). Responsibility Navigator. Governance framework for Responsible Research and Innovation. Karlsruhe: Res-AGorA Project.

Lacunza, I. (2020). Seminario Internacional, Nuevas Diplomacias 2020. Módulo de Diplomacia Científica. Sesión 3. Bogotá: Facultad de Finanzas, Gobierno y Relaciones Internacionales. Universidad Externado de Colombia.

Lloyd S., D. and Patman, R. G. (Eds.) (2015). Science Diplomacy: New Day or False Dawn, New Zealand: University of Otago.

López, A. \& Schunz, S. (19/10/2017). Understanding European Union science diplomacy. Obtenido de LSE Brexit http://eprints.lse.ac.uk/85573/1/ brexit-2017-10-19-understanding-europeanunion-science.pdf

Malacalza, B. (2017). A look inside an emerging nuclear supplier. Advocacy coalitions and change in Argentine foreign nuclear policy. Third World Quarterly, 38 (10). Pages 2295-2311

Mauduit, J.-C. and Gual Soler, M. (2020). Building a Science Diplomacy Curriculum. Frontiers in Education, 5:138. Doi: 10.3389/feduc.2020.00138.

McKinney, L. (2017). Continue U.S.-Cuban science diplomacy. Science, vol. 358, Issue 6370, pp. 1549. Doi: $10.1126 /$ science.aar7724

Megdal, S.B.; Varady, R.G. and Eden, S. (2012). Shared borders, shared waters: Israeli-palestinian and Colorado river basin water challenges. CRC Press.

Melchor, L. (2020). What is a science diplomat. The Hague Journal of Diplomacy, 15 (3), pp. 409-423

Melchor, L.; Elorza, A. and Lacunza, I. (2020). Calling for a Systemic Change: Towards a European Union Science Diplomacy for Addressing Global Challenges, vol. 1.0. s4D4C Policy Report, Madrid: 54D4C.

Meyer, J-B. and Brown, M. (1999). Scientific Diasporas: A New Approach to the Brain Drain, Mana- gement of Social Transformations (мо्т) program, Discussion Paper Series 41, prepared for the UNESCO- ICSU World Conference on Science, June 26-July 1, 1999, Budapest, Hungary, http://unesdoc.unesco.org/images/0011/001163/116330eo. pdf.

MinCiencias. (s.f.). Internacionalización. Obtenido de Ministerio de Ciencia, Tecnología e Innovación https://minciencias.gov.co/portafolio/internacionalizacion

Mojtahedi, Z. and Ghaderi, A. (2012). Proteomics studies in oncology towards personalized medicine in public health: Opportunities and challenges for OMICs research in Iran. Current Pharmacogenomics and Personalized Medicine, vol. 10, Issue 4, pp. 265-270.

Ordóńez-Matamoros, G. y Centeno, J. P. (2019). Editorial- Memorias del Congreso Internacional sobre Gobernanza de la Ciencia y la Innovación. Hacia el desarrollo inclusivo. Revista Innovación y Ciencia, 26 (2). Asociación Colombiana para el Avance de la Ciencia - Acac. Issn: 2590-8537. Disponible en https://innovacionyciencia.com/revista/101

Pantovic, B. y Michelini, G. (2018). Ciencia y cultura de la memoria en la diplomacia serbia. Revista Cidob d'Afers Internacionals, No. 120, pp. 241-258. Doi: doi.org/10.24241/rcai.2018.120.3.241

Ramírez-Cabrales, F. and Forero, S.I.R. (2020). Science Diplomacy: Strategic Initiative to Create a Buffer Zone in the Caribbean Colombian Marine Protected Area Seaflower. In: Rocha Á. and Pereira R. (eds.), Developments and Advances in Defense and Security. Smart Innovation, Systems and Technologies, vol. 152. Springer, Singapore.

Riordan, S. (2016). Diaspora Diplomacy: A Double Edged Sword, BideDao, June 6, Disponible en http://www.shaunriordan.com/?p=279. 
Ritch III, J. B. (1999). Nuclear green: Perspectives on science, diplomacy and atoms for peace. IAEA Bulletin, 41 (2), p. 2.

Ruffini, P. (2020). Collaboration and Competition: The Twofold Logic of Science Diplomacy, The Hague Journal of Diplomacy, 15 (3), 371-382. Doi: https://doi.org/10.1163/1871191X-BJA10028.

Rungius, C. (2018). State-of-the-art report: summarizing literature on science diplomacy cases and concepts. S4D4C Project. Obtenido de https:// www.s4d4c.eu/wp-content/uploads/2018/08/ S4D4C_State-of-the-Art_Report_DZHw.pdf

Rungius, C. \& Flink, T. (2020). Romancing science for global solutions: on narratives and interpretative schemas of science diplomacy. Humanities \& Social Sciences Communications, 7 (102), 1-10. Doi: https://doi.org/10.1057/s41599-020-00585-w

S4D4C. (2019). The Madrid Declaration on Science Diplomacy. Madrid: S4D4C. Obtenido de https://www. s4d4c.eu/s4d4c-1st-global-meeting/the-madriddeclaration-on-science-diplomacy/

Sabatier, P. (1988). An advocacy coalition framework of policy change and the role of policy-oriented learning therein. Policy Sciences, 21 (2), 129-168.

Sarkadi, B. and Schatten, G. (2012). Stem Cell Course in the Middle East: Science Diplomacy and International Collaborations During the Arab Spring. Stem Cell Reviews and Reports, 8 (1), pp. 87-90. Doi: 10.1007/s12015-011-9277-z

Saxenian, A. (2006). The New Argonauts: Regional Advantage In a Global Economy. Cambridge: Harvard University Press.

The Parliamentary Office of Science and Technology. (2018). Science Diplomacy - Postnote Number 568. London: Westminster.
The Royal Society. (2010). New frontiers in science diplomacy. Navigating the changing balance of power. London. Obtenido de https://royalsociety.org/ / / media/Royal_Society_Content/policy/publications/2010/4294969468.pdf

Timperley, C. M. et al. (2018). Advice from the scientific advisory board of the Organisation for the Prohibition of Chemical Weapons on isotopically labelled chemicals and stereoisomers in relation to the Chemical Weapons Convention. Pure and Applied Chemistry, 90 (10), pp. 1647-1670.

Turekian, V.; Macindoe, S.; Copeland, D.; Davis, L.; Patman, R. \& Pozza, M. (2015). The Emergence of Science Diplomacy. En L. Davis, \& R. Patman (Edits.), Science Diplomacy. New Day or False Dawn? Ciudad: World Scientific Publishing Company.

Turekian, V. (2018). The Evolution of Science Diplomacy. Global Policy, 9 (3). Doi: 10.1111/17585899.12622

Vikhlyaev, A. A. (2005). Science on the tap, not on the top. International Journal of Technology and Globalisation, 1 (2), pp. 145-161. Doi: 10.1504/ IJTG.2005.007048.

Pickett, W.E., Leggett, A.J. \& Chu, P.C.W. (2014). Science diplomacy in Iran. Nature Physics, 10 , pp. 465-467.

Wilder, M. et al. (2020). Hydrodiplomacy and adaptive governance at the U.S.-Mexico border: 75 years of tradition and innovation in transboundary water management. Environmental Science \& Policy, vol. 112, pp. 189-202. Disponible en https://doi. org/10.1016/j.envsci.2020.05.013 